\title{
MEDIA IKLAN PROFIL SMA-IT ALIA TANGERANG BERBASIS ANIMASI 3D
}

\author{
Dewi Immaniar ${ }^{1}$ \\ Triyono ${ }^{2}$ \\ Richi Setiawan ${ }^{3}$ \\ e-mail:dewi.immaniar@raharja.info,triyono@raharja.info, \\ richi.setiawan@raharja.info
}

Diterima : 04 Februari 2014 / Disetujui : 08 April 2014

\begin{abstract}
The development of multimedia technology, especially information technology today has grown more rapidly thereby making human life had now become so easy and fun . One area that can be combined with the development of the field of multimedia can be found in the advertising world, especially in education . Problems often occur advertising to promote the schools still less varied and less Mltimedia highlight developments that have been developed. The new breakthrough is needed, and in this case can be taken is a video profile which is often used as a medium for the introduction and promotion of schools in Indonesia. There are various types of advertising and video profiles are often produced, ranging from entirely ditokohkan and played by real human or using a 3D animation of characters that made ??such that it has the properties and behavior of human beings. By using Google Sketch up and 3D Max are arranged to create a frame by frame animation in the form of promotional advertising . Media Advertising Profile IT ALIA TANGERANG SMA - Based 3D Animation feature a wide range of excellence and achievement in high school there - IT ALIA . 3D advertising will reveal the main developments in the information technology IT ALIA high school that was already growing. This animation -based advertising media can contribute to increase the target of new students with a unique breakthrough advertising with $3 D$ animation .
\end{abstract}

Keywords : advertising , profiles , 3D animation

1. Dosen Jurusan Sistem Informasi, STMIK Raharja

Jl. Jend Sudirman No. 40 Modern Cikokol-Tangerang Telp. 5529692

2. Dosen Jurusan Sistem Informasi, STMIK Raharja

Jl. Jend Sudirman No. 40 Modern Cikokol-Tangerang Telp. 5529692

3. Mahasiswa Jurusan Sistem Informasi, STMIK Raharja

Jl. Jend Sudirman No. 40 Modern Cikokol-Tangerang Telp. 5529692 


\section{ABSTRAKSI}

Perkembangan teknologi informasi khususnya teknologi multimedia dewasa ini telah berkembang semakin pesat sehingga membuat kehidupan manusia sekarang ini menjadi sedemikian mudah dan menyenangkan. Salah satu bidang yang bisa dipadukan dengan adanya perkembangan bidang multimedia dapat ditemui dalam dunia periklanan khususnya dalam dunia pendidikan. Permasalahan yang sering terjadi iklan untuk mempromosikan sekolah-sekolah masih kurang variatif dan kurang menonjolkan perkembangan mltimedia yang sudah berkembang. Diperlukan terobosan baru, dan dalam hal ini dapat diambil adalah video profil yang sering kali digunakan sebagai media perkenalan dan promosi sekolah-sekolah di Indonesia. Terdapat berbagai jenis iklan dan video profil yang sering diproduksi, mulai dari yang seluruhnya ditokohkan dan diperankan oleh human real atau menggunakan animasi 3D berupa karakter yang dibuat sedemikian rupa sehingga mempunyai sifat dan tingkah laku layaknya manusia. Dengan menggunakan Google Sketch up dan 3D Max disusun frame per frame untuk menciptakan iklan promosi berupa animasi. Media Iklan Profil SMA-IT ALIA TANGERANG Berbasis Animasi 3D menampilkan berbagai macam keunggulan dan prestasi yang terdapat di sekolah SMA-IT ALIA. Utamanya iklan 3D akan menampakkan perkembangan teknologi informasi di SMA-IT ALIA yang memang sudah berkembang. Media iklan berbasis animasi ini dapat berkontribusi guna meningkatkan target siswa baru dengan terobosan iklan yang unik dengan animasi 3D.

Kata kunci : iklan, profil, animasi 3D

\section{PENDAHULUAN}

Multimedia adalah kombinasi dari komputer dan video (Rosch, 1996) atau Multimedia secara umum merupakan kombinasi tiga elemen, yaitu suara, gambar, dan teks (McCormick,1996) atau multimedia adalah kombinasi dari paling sedikit dua media input atau output dari data, media ini dapat audio (suara, musik), animasi, video, teks, grafik dan gambar (turban dkk. 2002) atau multimedia merupakan alat yang dapat menciptakan presentasi yang dinamis dan interaktif yang mengkombinasikan teks, grafik, animasi, audio dan gambar video (Robin dan Linda, 2001). Munculnya berbagai macam bentuk karya seni yang menggunakan aplikasi komputer sebagai sarana perencanaan dan perancangan sebuah karya, contohnya film dokumenter, profile film feature biografi seseorang, iklan, web design, dan berbagai bentuk rancangan komunikasi visual lainnnya. Sarana multimedia disebutsebut sebagai media komunikasi yang efektif dalam menyampaikan berbagai bentuk karya. Hal ini dibuktikan bahwa perancangan suatu karya seni dengan sarana multimedia meningkat lebih baik dari segi projek yang dihasilkan, sehingga dapat lebih menarik. 
Salah satu bidang yang dapat dipadukan dengan adanya perkembangan bidang multimedia tersebut adalah dunia pendidikan. Dalam hal ini dapat diambil sebagai contoh adalah iklan profil yang sering kali digunakan sebagai media perkenalan dan promosi sekolah-sekolah di Indonesia. Terdapat berbagai jenis iklan dan iklan profil yang sering diproduksi, mulai dari yang seluruhnya ditokohkan dan diperankan oleh human real hingga yang menggunakan animasi 3D atau kartun yang diperankan oleh tokoh-tokoh berupa karakter yang dibuat sedemikian rupa sehingga mempunyai sifat dan tingkah laku layaknya manusia.

Perbedaan iklan profil yang diperankan oleh human real dengan Animasi 3D terletak pada teknik pembuatannya, untuk menyelesaikan media iklan, dipilihlah animasi 3D karena dinilai lebih komunikatif, efektif, dan efisien. Promosi yang telah dilakukan oleh SMA-IT ALIA TANGERANG adalah melalu media cetak berupa brosur, spanduk, serta banner, oleh karenanya sebuah ide baru yang pada akhirnya akan diimplementasikan dengan hasil karya yang mencakup multimedia, audio visual and broadcasting. Sebuah iklan profil sebagai media yang dapat dipakai dalam mempresentasikan keunggulan SMA-IT ALIA TANGERANG, iklan profil yang telah dibuat akan dipublikasikan pada acara ALIA Fair, ditampilkan pada blog/web SMA-ITALIA TANGERANG, serta untuk dijadikan merchandise bagi para calon peserta didik dengan durasi kurang lebih sekitar 1-2 menit. Berdasarkan latar belakang permasalahan diatas, maka diambil topik "Media iklan profil Pada SMAIT ALIA TANGERANG Berbasis Animasi 3D”, yang menceritakan mengenai keunggulan-keunggulan SMA-IT ALIA TANGERANG.

Berbeda dengan konsep media yang telah maupun sedang berjalan, bahwa video iklan mengambil ide dari struktur bangunan yang ada pada SMA-IT ALIA TANGERANG, dengan menampilkan fasilitas serta keunggulan yang dipunyai oleh SMA-IT ALIA TANGERANG sehingga dari hasil animasi bergerak mampu mengajak penonton untuk lebih jelas dalam memahami informasi mengenai SMAIT ALIATANGERANG.

\section{LANDASAN TEORI}

Pengertian Media (Tjiptono, Fandi, 2009 : 240). Media adalah aneka sarana komunikasi yang dipakai untuk mengantar dan menyebarluaskan pesan komersial kepada khalayak sasaran atau dapat dikatakan salah satu periklanan yang dilakukan melalui saluran media tertentu, seperti brosur, spanduk, media luar ruang. Disebutkan 
oleh (Kotler, 2009 : 658), periklanan didefinisikan sebagai bentuk penyajian dan promosi ide, barang atau jasa secara nonpersonal oleh suatu sponsor tertentu yang memerlukan pembayaran. Sedangkan menurut (Rhenald Kasali, 2010 : 21), secara sederhana iklan didefinisikan sebagai pesan yang menawarkan suatu produk yang ditujukan oleh suatu masyarakat lewat suatu media. Namun demikian, untuk membedakannya dengan pengumuman biasa, iklan lebih diarahkan untuk membujuk minat seseorang. Iklan salah satunya dengan menggunakan animasi. Menurut (Kuswara. 2009 : 3) Animasi berasal dari bahasa latin, anima yang artinya jiwa, hidup, nyawa dan semangat. Animasi adalah gambar dua dimensi yang seolah-olah bergerak. Animasi ialah suatu seni untuk memanipulasi gambar menjadi seolah-olah hidup dan bergerak, yang terdiri dari animasi 2 dimensi maupun 3 dimensi. Animasi 2D membuat benda seolah hidup dengan mengunakan kertas atau computer

Menurut (Djalle, Zaharuddin. Purwantoro, Edi. Dasmana, Demi. 2010. 3D Animation Using 3DStudioMax. Bandung: Penerbit Informatika Bandung) Definisi animasi sendiri berasal dari kata 'to animate' yang berarti menggerakkan, menghidupkan. Misalkan sebuah benda yang mati, lalu digerakkan melalui perubahan sedikit demi sedikit dan teratur sehingga memberikan kesan hidup. Animasi adalah proses penciptaan efek gerak atau efek perubahan bentuk yang terjadi selama beberapa waktu. Animasi juga merupakan suatu teknik menampilkan gambar berurut sedemikian rupa sehingga penonton merasakan adanya ilustrasi gerakan (motion) pada gambar yang ditampilkan. Definisi tersebut mengartikan bahwa benda-benda mati dapat ‘dihidupkan’. Pengertian tersebut hanyalah merupakan istilah yang memiripkan, dalam arti tidak harus diterjemahkan secara denotatif, melainkan simbol yang menyatakan unsur kedekatan.

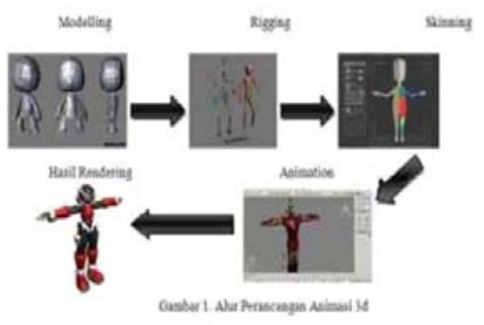

Gambar 1. Alur Perancangan Animasi 3d

Dari gambar 1 diatas menurut (Suyanto, M. Yuniawan, Aryanto. 2010) implementasi 3D memiliki beberapa tahapan yang diantaranya adalah(a). Modelling dan texturing, dalam tahapan modeling dan texturing ini, software yang digunakan 
adalah Autodesk 3Ds max 2009, yang mempunyai fasilitas yang cukup lengkap dalam pembuatan modeling atau penganimasian. Untuk modeling karakter, environtment dan property, penulis menggunakan teknik low poly modeling, cara ini adalah dengan menggunakn model baku yang sudah ada pada 3D studio max yaitu box, kemudian dibentuksesuai desain; (b). Skeletal Setup (Rigging) adalah pemberian rangka pada karakter. Dalam pemberian karakter, menggunakan biped yang berfungsi untuk menganimasikan pergerakan karakter secara cepat yang disediakan oleh Autodesk 3ds max 2009; (c). Skinning adalah proses penyatuan rangka ke badan karakter. Pada proses skinning ini menggunakan modifier Physique; (d). Animation, Pada tahap ini membuat animasi secara manual pada karakter yang sudah dibuat; (e). Rendering adalah proses akhir dari keseluruhan proses pemodelan. Dalam rendering, semua data-data yang sudah dimasukkan dalam proses modeling, animasi, texturing, pencahayaan dengan parameter tertentu akan diterjemahkan dalam sebuah bentuk output

\section{LITERATURE REVIEW}

Dalam upaya video animasi ini perlu dilakukan studi pustaka sebagai salah satu dari penerapan metode penelitian yang akan dilakukan. Diantaranya adalah mengidentifikasi kesenjangan (identify gaps), menghindari pembuatan ulang (reinventing the wheel), mengidentifikasi penelitian yang sama dibidang ini beberapa literature review tersebut adalah sebagai berikut :

1. Penelitian yang dilakukan oleh Suryandi Sedyo Utami "Pemanfaatan Bahan Ajar Sistem Informasi Akuntansi Berbasis Multimedia Interaktif”, mengenai sistem informasi yang berbasis multimedia dapat digunakan sebagai media pembelajaran perancangan pembelajaran berbasis multimedia interaktif pada mata kuliah sistem informasi Akuntansi dirancang sedemikian rupa berdasarkan kebutuhan dosen dan mahasiswa dengan menggunakan Macromedia authorware. Program ini berbasis informasi materi dalam bentuk teks, suara, gambar, video maupun gambar animasi

2. Penelitian yang dilakukan oleh Moch Adhi Nugraha (2009) berjudul "PERANCANGAN PROSEDUR KKP DAN TA/SKRIPSI DENGAN MENGGUNAKAN MEDIA AUDIO VISUAL PADA PERGURUAN TINGGI RAHARJA”. Saat ini, Prosedur KKP, TA/Skripsi hanya berupa buku pedoman yang diberikan kepada mahasiswa/i, namun didalam prosesnya sering terjadi keterlambatan cetak buku panduan KKP, TA/Skripsi yang akan di terima oleh mahasiswa, sehingga KKP, TA/Skripsi sudah berjalan namun 
mahasiswa belum mendapat acuan yang pasti dalam membuat laporan KKP, TA/Skripsi. Selain itu dengan tampilan Animasi akan lebih menarik, dan membantu kebutukan mahasiswa dalam memperoleh informasi detail dan up to date yang diberikan dari pihak akademik.

3. Sedangkan penelitian yang dilakukan M. Nur Kholis, berjudul Perancangan Media Iklan Konsentrasi Multimedia Audio Visual And Broadcasting Pada Jurusan Teknik Informatika Perguruan Tinggi Raharja mengenai Sarana multimedia sebagai alat komunikasi mempunyai peranan yang sangat penting dalam menginformasikan sesuatu kepada masyarakat, hal ini dinilai sangat komunikatif dan efektif disaat mobilitas manusia yang semakin tinggi sehingga dibutuhkan bentuk media komunikasi yang menarik dan lebih interaktif yang ditujukan kepada masyarakat, dan banyak cara untuk menyampaikan suatu informasi yang diolah ke dalam bentuk multimedia agar terlihat lebih menarik dalam penyampaiannya. Dalam kesempatan tugas skripsi ini, penulis mengangkat topik permasalahan yang diberi judul Perancangan Media Iklan Multimedia Audio Visual And Broadcasting Pada Jurusan Teknik Informatika Perguruan Tinggi Raharja.

4. Penelitian yang dilakukan Birawan Dwi Nurrahman berjudul Perancangan Media Video Profil Tentang Biografi Drs. Po. Abas Sunarya, M.Si. mengenai perancangan media profil. Biografi merupakan identitas, ciri-ciri khusus atau image suatu lembaga atau perusahaan maupun perorangan yang biasa digunakan sebagai tanda pengenal dalam melakukan komunikasi yang hendak disampaikan oleh seseorang, baik dalam lingkup intern atau perusahaan maupun dengan instansi ataupun pihak-pihak terkait lainnya diluar lingkungan perusahaan tersebut. Maka penulis mengusulkan kepada Drs. Po. Abas Sunarya, M.Si. untuk membuat video biografi, yang merupakan sebagai media penyampaian informasi kepada khalayak yang dapat di jadikan sebagai aset perorangan maupun lembaga atau perusahaan yang terkait sehingga dapat digunakan untuk meningkatkan suatu image atau citra orang (tokoh) tersebut maupun dari perusahaan untuk menjalin kerja sama dengan relasi perusahaan, lembaga dan instansi terkait lainnya. Maka dari itu dituangkanlah sebuah desain tersebut dalam sebuah laporan skripsi yang berjudul "Perancangan Media Video Profile Tentang Biografi Drs. Po. Abas Sunarya, M.Si.”. Harapannya adalah agar laporan ini dapat bermanfaat dan berguna bagi Perguruan Tinggi Raharja khususnya kepada Bapak Drs. Po. Abas Sunarya, M.Si.

5. Penelitian yang dilakukan oleh Lima Apriyani (2010) berjudul "PERANCANGAN VIDEO COMPANY PROFILE SEBAGAI MEDIA INFORMASI DAN PROMOSI PADA PT. MELIA NATURE 
INDONESIA”. Saat ini, presentasi hanya dilakukan dengan menggunakan media berupa buku dan katalog yang diberikan kepada calon member, namun didalam prosesnya sering terjadi pemahaman yang menyimpang dan tidak fokusnya calon member dalam menerima informasi yang mengakibatkan gagalnya proses presentasi. Karena itu dengan tampilan Animasi yang ada dalam media presentasi akan membuat proses presentasi lebih menarik, dan membantu kebutuhan member dalam memperoleh informasi yang lebih detail tentang PT. Melia Nature Indonesia.

Kesimpulan yang bisa diambil bahwa Video Profil merupakan pesan yang menawarkan suatu produk yang ditujukan oleh suatu masyarakat lewat suatu media. Hasil studi pustaka (literature review) ini mendemonstrasikan landasan yang kokoh serta alasan yang kuat untuk mengembangkan Sistem informasi media iklan dalam penyampaian informasi dan promosi menjadi lebih baik lagi dengan pertimbangan yang lebih matang. Kesenjangan (gaps) telah teridentifikasi dengan baik sehingga tidak terjadi pembuatan ulang (reinventing the wheel). Peninjauan telah dilakukan dengan matang, sehingga akan menghasilkan project yang lebih efektif dan berkontribusi banyak kepada stakeholder dengan peningkatan target siswa baru hungga stakeholder merasa puas. Setelah melakukan analisa terhadap permasalahan yang ada maka terwujudlah sebuah usulan kepada SMA-IT ALIATANGERANG untuk membuat sebuah Video Profil, yaitu suatu karya desain yang dikemas dalam bentuk audio visual yang merupakan sebagai media promosi untuk menarik minat masyarakat untuk menjadi siswa-siswi.

\section{METODOLOGI PENELITIAN}

Pelaksanaan penelitian yang dilakukan, untuk merancang project animasi ini adalah

1) Metode Observasi adalah Suatu metode pengumpulan data dengan cara melakukan pengamatan secara langsung terhadap objek penelitian, yaitu pada SMA-IT ALIATANGERANG;

2) Metode Interview adalah suatu metode untuk mendapatkan data dengan cara wawancara atau tanya jawab secara lisan yang dilakukan dua orang atau lebih, yang berhubungan dengan penelitian. Dengan metode ini penulis mendapatkan informasi-informasi dengan melakukan tanya jawab dengan Guru maupun Staff yang bersangkutan mengenai obyek yang akan dibuat untuk mendapatkan informasi yang diperlukan; 
3) Metode Pustaka, Metode ini merupakan jenis penelitian yang berdasarkan pada buku-buku, literatur, browsing internet, sebagai acuan untuk mendapatkan suatu data atau sebagai panduan di dalam melakukan penelitian.

\section{PEMBAHASAN}

\section{Analisa Market}

Dalam membuat media iklan yang baik maka ditentukan 3 aspek yang melibatkan potensial market, marketing objective dan marketing strategi.

a).Pontensial market dari Sekolah SMA/SMK ini berada di wilayah Tangerang Banten, dengan pangsa pasar yang cukup banyak terdapat di daerah Dasana Indah, Legok, dan BSD. Target promosi lembaga pendidikan pada tahuntahun berikutnya diperkirakan akan meningkat. Karena banyaknya sekolahsekolah yang baru berdiri, biasanya sekolah yang baru berdiri tersebut membutuhkan media iklan sebagai penunjang promosi. Oleh karena itu SMAITALIATANGERANG memiliki peluang yang besar untuk mempromosikan lembaga pendidikanya melalui iklan profil yang dikemas dalam bentuk audio visual (video);

b).Marketing Objektif ( Tujuan Pemasaran ) Dalam memberikan media informasi dan promosi tentang profil SMA-ITALIA TANGERANG kepada konsumen (calon peserta didik baru, relasi maupun masyarakat) bagian marketing menambah sarana promosi, yaitu dengan media iklan profil karena media informasi promosi yang digunakan sebelumnya (brosur) masih kurang lengkap, oleh sebab itu media iklan profil dirancang secara detail dan menarik agar dapat meningkatkan jumlah calon peserta didik baru yang sesuai target;

c). Marketing Strategi (Strategi Pemasaran) Strategi komunikasi pemasaran disini berkaitan dengan strategi promosi. Strategi Promosi berhubungan dengan masalah-masalah perencanaan, pelaksanaan dan pengendalian komunikasi persuasif dengan konsumen yang biasanya untuk menentukan pengeluaran promosi, bentuk promosi dan pemilihan media.

\section{Preproduction}

Ada beberapa langkah Preproduction dalam pembuatan Media Iklan pada SMA-IT ALIA TANGERANG, dimulai dari observasi lapangan dengan mengumpulkan data-data yang diperlukan, kemudian yang dituangkan dalam sebuah 
ide/gagasan secara sistematis agar menghasilkan pesan dari media iklan itu sampai kepada penonton, lalu diikuti dengan pembuatan sinopsis, Script Writting dan Storyboard. Dua tahapan terakhir adalah pemilihan dubbing/crew dan Setting Alat. Semua tahapan yang ada harus sesuai Time Schedule yang ditetapkan. Untuk lebih jelasnya di ilustrasikan pada bagan berikut ini:

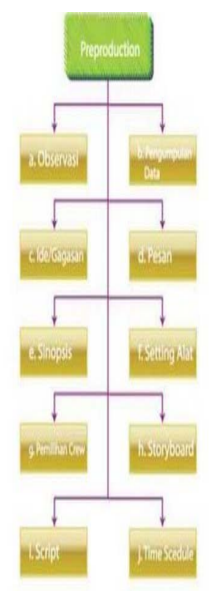

Gambar 2. Bagan Preproduction

a). Observasi ialah Pengamatan yang dilakukan secara khusus pada SMA-IT ALIATANGERANG mengenai media promosi yang pernah dibuat, beberapa media yang pernah atau sedang berjalan diantaranya adalah promosi melalui brosur, spanduk, kalender, stiker, dan lain-lain;

b). Pengumpulan data dilakukan dengan mencari referensi yang dibuat oleh salah satu mahasiswanya kemudian dijadikan referensi untuk pembuatan video iklan pada SMA-IT ALIA TANGERANG. Beberapa data yang berhasil dikumpulkan, mengenai permasalahan pada SMA-ITALIA TANGERANG, sesuai tujuan penelitian adalah mengenai media promosi yang diterapkan di sekolah itu. Media promosi yang sering dipakai biasanya menggunakan spanduk, brosur, kalender, dan stiker, permasalahan yang sering terjadi ketika pembaca hanya melihat sebagian fasilitas-fasilitas yang berupa foto-foto, sehingga pembaca tidak ikut hanyut dalam memaknai informasi yang disajikan;

c). Ide atau Gagasan yang didapat dari hasil referensi media promosi, berupa video iklan pada Universitas/Perguruan Tinggi di Indonesia diantaranya UPH, STMIK Raharja, BSI, UNY dan lainnya. Konsep yang ingin ditampilkan dalam video iklan ini tidak jauh berbeda dengan isi yang ada didalam brosur. 
Keunggulannya terletak dari pemahaman masyarakat bahwa di era globalisasi seperti sekarang ini, orang-orang cenderung menilai dari tampilan awal/iklan yang disajikan dengan semenarik mungkin, sedikitnya menunjukkan kualitas multimedia yang dipunyai oleh SMA-ITALIATANGERANG, sehingga dapat menarik para orang tua untuk mendaftarkan anaknya di SMA-IT ALIA TANGERANG;

d). Pesan berbeda dengan konsep media yang telah maupun sedang berjalan, bahwa video iklan mengambil ide dari struktur bangunan yang ada pada SMAITALIATANGERANG, dengan menampilkan fasilitas serta keunggulan yang dipunyai oleh SMA-IT ALIA TANGERANG sehingga dari hasil animasi bergerak mampu mengajak penonton untuk lebih jelas dalam memahami informasi mengenai SMA-IT ALIA TANGERANG;

e). Sinopsis SMA-IT ALIA TANGERANG memiliki keunggulan dari segi Keagamaan dan Teknologi yang merupakan sekolah yang diminati calon peserta didik baru. Dari kegiatan-kegiatan pembuatan video iklan membuktikan sekolah tersebut memiliki kreatifitas, kualitas dan berkembangnya sekolah tersebut. Video iklan ini dibuat dengan mengambil letak wilayah SMA-IT ALIA TANGERANG melalui Google Earth, dimaksudkan agar calon peserta didik baru maupun orang tua murid dapat mengetahui di daerah mana SMAITALIATANGERANG itu berada. Kemudian dengan menampilkan gedung utama SMA-ITALIA TANGERANG yang begitu kokoh dan nyaman diikuti ruangan-ruangan yang dimiliki SMA-IT ALIA TANGERANG agar orang tua murid dapat menggambarkan bagaimana keadaan sekolah yang nantinya akan menjadi tempat anak-anak mereka menuntut ilmu, selanjutnya menampilkan kegiatan-kegiatan SMA-ITALIATANGERANG yang mereka tidak hanya disibukkan dalam pelajaran melainkan diiringi kegiatan yang akan menambah wawasan mereka, contohnya Outing Class hampir 2-3 kali dalam 1 semester, para peserta didik turun ke lapangan dan mengambil pelajaran. Dalam video iklan ini menjelaskan pula staf pengajar SMA-IT ALIA TANGERANG disertai lulusannya;

f). Time Schedul, berikut adalah time schedule yang dipakai untuk membuat iklan animasi 3D untuk SMAAlia IT 
Tabel 1. Time Schedule produksi media iklan dengan special effect

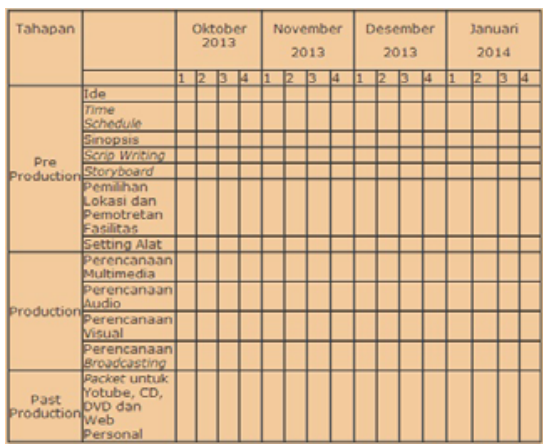

g). Script Writting, membuat rancangan penulisan naskah secara rinci yang mengembangkan gagasan pada sinopsis menjadi sebuah konsep yang menarik. Script Writing dalam video iklan ini adalah:

\section{Tabel 2. Script Writing}

\begin{tabular}{|c|c|c|}
\hline No & Take Script & Ket \\
\hline 1 & Take Songt 1 & Bumper SMA-II Ala Tangerang \\
\hline 2 & Take Sonpt 2 & Ste plan wlayah SMA.TI ALa Tangenno \\
\hline 3 & Take Script 3 & hnimasi Gedung Utama \\
\hline 4 & Take Scrips 4 & hrimasi Ruang Kelas \\
\hline 5 & Take Scrigk 5 & Animasi Kantor Utama \\
\hline 5 & Take Sorigt 6 & Animasi Masid \\
\hline 7 & Take Seript 7 & Grimasi Lab. Komputer \\
\hline 3 & Take Scrigr 8 & Penjelasan Sekolah \\
\hline 9 & Take Script 9 & Penjedasan Prestasi \\
\hline 10 & Take Script 10 & Wdeo Kegatan \\
\hline II & Take Schot 11 & Penjelisan Pendaftaran \\
\hline 12 & Take Script 12 & Clossing Promosi Peserto Diflk \\
\hline 13 & Take Script 13 & Penjolasan Alamat lengkap \\
\hline 14 & Take Script 14 & LOOO STMD RAHAR2A \\
\hline 15 & Take Sorig 15 & Credit Tithe \\
\hline
\end{tabular}

h). Storyboard merupakan rancangan berupa sket gambar yang dilengkapi dengan petunjuk atau catatan pengambilan gambar untuk kebutuhan shooting. Selama proses praproduksi, perencanaan yang berhubungan dengan visualiasasi yang akan dibuat membutuhkan Storyboard sebagai media bantuannya.

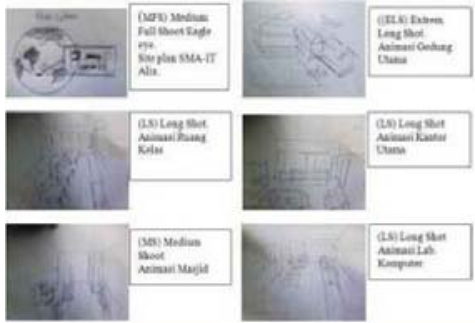

Gambar 3. Storyboard Media Iklan 
i). Pemilihan Pemain dan Crew Pemain dicari sesuai dengan karakter dari tokoh yang terdapat pada Storyline. Pemain yang tidak sesuai akan mengurangi kualitas dari video iklan yang dibuat. Sedangkan untuk Crew secara garis besar dibutuhkan Cameramen, Sutradara, Editor, Dubbing; j). Setting Alat Secara umum alat yang dibutuhkan adalah Camera. Untuk Camera yang digunakan penulis menggunakan Camera Digital Canon 10 Megapixel. Sedangkan Lighting kurang dibutuhkan karena pengambilan gambar untuk video iklan ini di ruangan outdoor. Sedangkan Mic com digunakan dalam pengisian dubbing suara kedalam iklan melalui komputer.

Production adalah tahapan dimana pengambilan gambar atau shooting dilakukan. Dalam production pada tahapan project ini dibagi menjadi:

a). Perencanaan Visual, Bentuk visualisasi yang dihasilkan nantinya akan berupa karya visual atau dalam bentuk video. Perencanaan visual ditujukan guna memberikan kesan dan image dalam video iklan yang ditampilkan. Dengan visual effects dapat memberikan Image yang menunjukan SMA-IT ALIA TANGERANG berkembang dan banyak diminati. Untuk mencapai perencanaan visual yang baik dibuat Tujuan Visual sebagai arahan mencapai visualisasi yang terkonsep. Tujuan Visual sabagai acuan untuk menampilkan kesan dan image apa yang ingin ditonjolkan dari ditampilkannya video iklan. Untuk mencapai Tujuan visual diperlukan Strategi Visual sebagai langkah yang diperlukan dalam mencapai Tujuan Visual. Strategi Visual meliputi teknik dan metode yang dipakai dalam video iklan. Sedangkan Program Visual merupakan step mewujudkan perencanaan visual dengan diproduksinya program visual diartikan perencanaan visual telah tercapai. Program Visual meliputi teknik pengambilan gambar, efek-efek visual yang digunakan dalam mewujudkan Tujuan Visual dengan menggunakan Metode dan teknik yang telah dijabarkan dalam strategi Visual;

b). Tujuan Visual, Media iklan yang dirancang berupa sebuah karya visual yang didalamnya terdapat visual effects sehingga dapat menciptakan suatu bentuk visulisasi yang terkesan. Banyak kesan yang terdapat dalam kehidupan seharihari, diantaranya: Kesan Klasik, Kesan Resmi, Kesan Modern, Kesan Female, dan masih banyak lagi. Namun dalam pembuatan video iklan sebagai penunjang informasi hanya akan mengambil beberapa kesan yang sekiranya akan mempercantik dan memperkaya tampilan. lihat table 4;

c). Strategi Visual,Visual Effects dapat diciptakan dengan bantuan teknologi komputer yang sudah sangat maju sekarang ini, sehingga memberikan suatu bentuk pencitraan riil atau benar - benar nyata terhadap gambaran visualisasi 
pada video tersebut. Momen yang ditampilkan berupa acara dan fasilitas di SMA-IT ALIA TANGERANG, semua tampilan tersebut dikemas dan disajikan dengan menggunakan pendekatan Rasional, Emosional dan Positif dengan gaya penyajian yang menimbulkan kesan Modern dan Teknologi. Semua dirancang dan disajikan dengan tepat, tegas, dan efektif;

Tabel 3. Kesan Visual effect

\begin{tabular}{|l|l|}
\hline \multicolumn{1}{|c|}{ Visual Effect } & \multicolumn{1}{c|}{ Kesan yang ditimbulkan } \\
\hline Bumper Judul Karya & Semangat, Ceria, Cerah \\
\hline Animasi Gedung Utama & Semangat, Menarik \\
\hline Animasi Ruang kelas & Klasik \\
\hline Animasi Kantor Utama & $\begin{array}{l}\text { Kesan Teknologi, Kesan Modern, Kesan } \\
\text { Menarik }\end{array}$ \\
\hline Aniamsi Gedung Masjid & Minimalis \\
\hline
\end{tabular}

d). Program Visualisasi, didalam proses produksi inilah perancangan Spesial Effects dibuat menggunakan aplikasi-aplikasi yang merupakan hasil dari kemajuan teknologi. Acuan Storyboard diubah menjadi animatrix yaitu semacam slide show dari Storyboard yang sudah diisi dengan dialog yang belum diedit. Ada beberapa tahapan dalam program Visual yaitu diantaranya:

1. Site plan melalui Google Earth

Pada iklan ini ditampilkan site plan SMA-ITALIATANGERANG melalui Google Earth yang dimaksudkan untuk menampilkan wilayah, agar masyarakat umum dapat dengan jelas mencari letak SMA-IT ALIA TANGERANG.

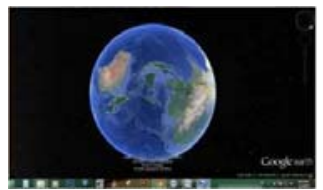

Gambar 4. Site Plan SMA-IT ALIA TANGERANG

2. Gedung Utama

Gedung Utama dibuat menggunakan 3ds Max 2009 agar tampilan gedung sebisa mungkin menyerupai bangunan aslinya, ditambah sedikit effect suara agar terkesan ceria, dan semangat. Konsep yang dipakai dalam pengambilan video animasi adalah dengan Eagle eyes (mata elang), dimaksudkan untuk memberi kesan gedung terlihat dari atas. 


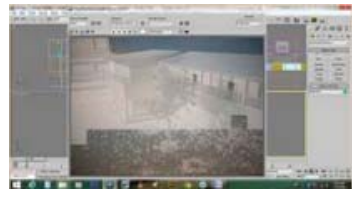

Gambar 5. Modelling

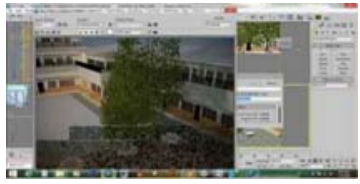

Gambar 6. Rendering

3. Ruang Kelas

Ruang Kelas masih dibuat dengan software utama yaitu 3ds Max, tetap meniru ruang kelas yang sebenarnya. Dengan aplikasi 3ds Max kita dapat membuat visual bangunan sesuai yang diinginkan, kemudian untuk memberikan effect real digunakan software tambahan vray 2.02.

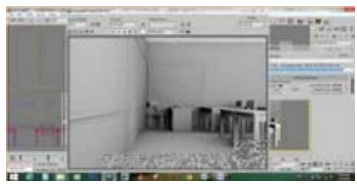

Gambar 7. Modelling

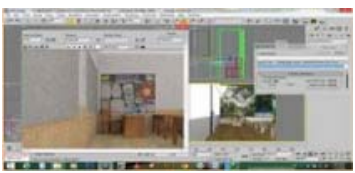

Gambar 8. Rendering

\section{Ruang Kantor Utama}

Dengan gaya minimalis modern, Ruang kantor utama menyajikan kenyamanan bagi pengunjung yang ingin mendaftarkan anaknya, dan dilenkapi tempat pembayaran, sehingga peserta didik tidak perlu mengantri dengan berdiri. Software yang digunakan Google SketchUp dan vray agar lebih realistis.

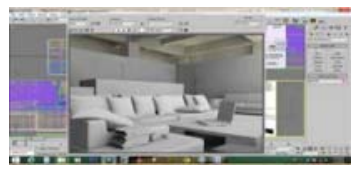

Gambar 9. Modelling 


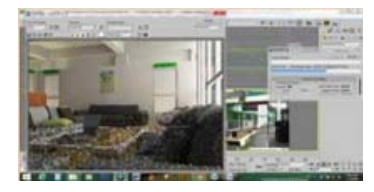

Gambar 10. Rendering

\section{Gedung Masjid}

SMA-ITALIATANGERANG dilengkapi dengan berbagai fasilitas penunjang diantaranya Masjid Imam Syafi'i, sehingga peserta didik maupun guru dan staff SMA-ITALIA TANGERANG bisa sholat berjamaah, dan sholat sunnah lainnya. Beberapa software yang digunakan untuk membuat bangunan diantaranya Google Sketchup, 3ds Max, dan untuk pengeditan menggunakan Adobe Premier dengan tambahan sound effect.

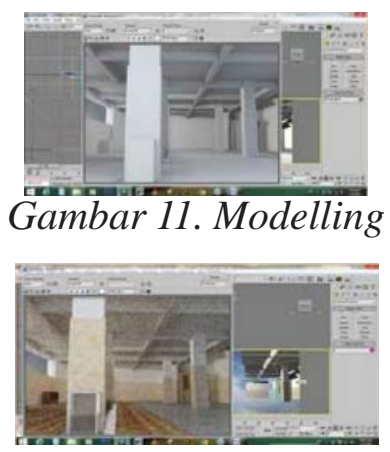

Gambar 12. Rendering

6. Ruang Lab Komputer

Konsep yang ditampilkan pada Lab Komputer menggunakan gaya klasik, dengan menampilkan warna-warna coklat yang dihiasi kayu-kayu pada kursi dan bangkunya. Sedikit effect yang diberikan untuk pengeditan video dengan menambahkan sound effect.

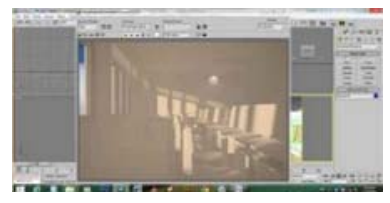

Gambar 13. Modelling 


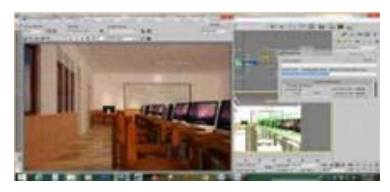

Gambar 14. Rendering

\section{KONFIGURASI PERANCANGAN}

Untuk membuat perancangan yang baik maka dibutuhkan bantuan aplikasi dan hardware yang mumpuni. Untuk itu sangat direkomendasikan mempunyai Spesifikasi Hardware dengan spesifikasi Processor Intel(R) Core(TM) i3-2330M CPU @2.20GHz, Monitor Generic PnP Monitor 1190 MB, Mouse Logitech Optical Mouse, RAM 4 Gb, Harddisk 500 Gb, Keyboard Easy Touch. Software Yang Digunakan dalam Konsep media informasi dan promosi tersebut, penulis menggunakan software Autodesk 3ds Max 2009 32-bit, Google SketchUp 8 dan Adobe Premiere Pro CS3.

Software yang digunakan adalah Autodesk 3ds Max 2009 32-bit adalah program untuk mengambar yang berbasis vektor 3 dimensi dan animasi , dimana user dapat dengan mudah membuat suatu film animasi, arsitektur rumah, ataupun membuat logo suatu perusahaan. 3d Studio Max dikembangkan dari pendahulunya yaitu 3D Studio for DOS.

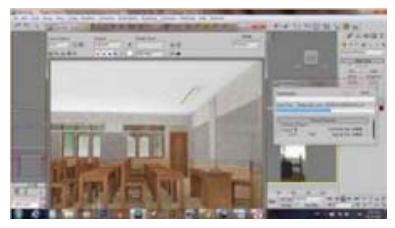

Gambar 15. Software 3ds Max 2009

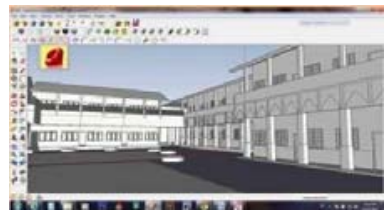

Gambar 16. Software SketchUp Pro 8

Google SketchUp 8 sama halnya dengan 3ds Max, program ini digunakan untuk membuat gambar berbasis vektor 3 dimensi dan animasi bangunan, Google 
SketchUp 8 sering digunakan oleh para drafter dan arsitek untuk menggambar visual bangunan, karena fasilitas-fasilitas di dalamnya dapat digunakan untuk membentuk objek secara tiga dimensi, sehingga hasil yang diperoleh menyerupai objek yang sebenarnya.

Adobe Premiere Pro CS3 merupakan salah satu aplikasi video editing yang banyak digemari dan digunakan, baik oleh penyunting video amatir ataupun prfoesional, karena aplikasi ini menyediakan fasilitas yang sangat beragam dan mudah digunakan.

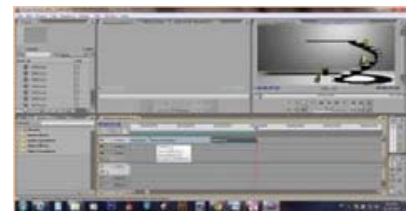

Gambar 17. Software Adobe Premiere Pro

\section{KESIMPULAN}

Berdasarkan uraian diatas, disimpulkan bahwa Media Iklan Profil untuk SMA-IT Alia Tangerang Berbasis Animasi 3d merupakan media yang sangat tepat untuk meningkatkan minat menarik calon siswa baru. Informasi lebih cepat ditangkap serta durasi tampung informasi lebih lama diingat karena melibatkan dua sensor indra sekaligus yaitu audio dan visual, hal ini pun berhubungan dengan fungsi kerja otak manusia. Dimana ketertarikan masyarakat juga akan lebih mendalam karena dikaitkan dengan effect-effect animasi yang akan lebih melekat secara emosional. Adapun kesimpulan yang diperoleh selama penelitian dan perancangan desain yaitu :Untuk melengkapi bentuk media promosi yang telah digunakan hingga saat ini, maka sesuai dengan kesepakatan melalui interview yang dilakukan penulis kepada pihak terkait, maka perlu dikembangkan bentuk media iklan yang mempunyai terobosan baru. Adapun bentuk media iklan yang ditampilkan ialah dengan media iklan 3DS Max. Agar media iklan dapat membentuk citra positif untuk image sekolah, perancangan haruslah memperhatikan prinsip-prinsip yang terdapat dalam desain grafis dan identitas yang menjadi ciri khas dari perusahaan tersebut serta material yang digunakan yang kesemuanya disatukan dalam bentuk keseragaman dan konsistensi dalam setiap itemnya. 


\section{DAFTAR PUSTAKA}

[1] Adhi, Moch Nugraha. Perancangan Prosedur KKP dan Ta/Skripsi Dengan Menggunakan Media Audio Visual Pada Perguruan Tinggi Raharja. Stmik Raharja. 2009

[2] Apriyani, Lima. Perancangan Video Company Profile Sebagai Media Informasi Dan Promosi Pada Pt. Melia Nature Indonesia. Stmik Raharja. 2010

[3] Atmohoetoem, Media Audio Visual, 2011.

[4] Djalle, Zaharuddin. Purwantoro, Edi. Dasmana, Demi. 3D Animation Using 3DStudioMax, Bandung. Penerbit Informatika Bandung. 2010

[5] Kotler. Media Iklan dan Periklanan. 2010.

[6] McCormick. Kombinasi Dari Komputer Dan Video. 1996.

[7] Robin dan Linda. Dinamis Dan Interaktif yang Mengkombinasikan Teks, Grafik. 2001.

[8] Rosch. Kombinasi Dari Komputer Dan Video. 1996.

[9] Suprapto, Tommy. Berkarier di bidang Broadcasting. Media Pressindo. Yogyakarta. 2009.

[10] Suyanto, M. Yuniawan, Aryanto. Merancang Film kartun kelas Dunia. Yogyakarta. Penerbit Andi Offset. 2010.

[11] Tjiptono, Fandy. Strategi Pemasaran. Andi Offset, Yogyakarta. 2008. hal. 219-232

[12] Turban dkk. Kombinasi media input, output. 2002. 